Case Report

\title{
Primary Neuroendocrine Breast Carcinoma in a 13-Year-Old Girl: Ultrasonography and Pathology Findings
}

\author{
Mazamaesso Tchaou, ${ }^{1}$ Tchin Darré, ${ }^{2}$ Koué Folligan, ${ }^{3}$ \\ Akomola Sabi, ${ }^{4}$ Lantam Sonhaye, ${ }^{1}$ Azanledji Boumé, ${ }^{5}$ Akila Bassowa, ${ }^{6}$ \\ Solange Adani-Ifé, ${ }^{7}$ and Gado Napo-Koura ${ }^{2}$ \\ ${ }^{1}$ Department of Radiology, The University Teaching Hospital of Lomé, Lomé, Togo \\ ${ }^{2}$ Department of Pathology, The University Teaching Hospital of Lomé, Lomé, Togo \\ ${ }^{3}$ Department of Histology-Embryology, The University Teaching Hospital of Lomé, Lomé, Togo \\ ${ }^{4}$ Department of Endocrinology and Nephrology, The University Teaching Hospital of Lomé, Lomé, Togo \\ ${ }^{5}$ Department of Pediatric Surgery, The University Teaching Hospital of Lomé, Lomé, Togo \\ ${ }^{6}$ Department of Obstetrics and Gynecology, The University Teaching Hospital of Lomé, Lomé, Togo \\ ${ }^{7}$ Department of Clinical Oncology, The University Teaching Hospital of Lomé, Lomé, Togo
}

Correspondence should be addressed to Mazamaesso Tchaou; joseph_tchaou@yahoo.fr

Received 15 May 2017; Revised 17 July 2017; Accepted 7 August 2017; Published 10 September 2017

Academic Editor: Samer Ezziddin

Copyright (C) 2017 Mazamaesso Tchaou et al. This is an open access article distributed under the Creative Commons Attribution License, which permits unrestricted use, distribution, and reproduction in any medium, provided the original work is properly cited.

\begin{abstract}
Neuroendocrine carcinoma (NEC) of the breast is a rare disease and has been scarcely reported by African authors. The authors report a case of breast NEC in a 13-year-old African girl initially diagnosed as an atypical adenofibroma by ultrasonography. Ultrasound-guided biopsy and conventional histological examination indicated two potential diagnoses: primary malignant nonHodgkin's lymphoma and undifferentiated carcinoma. According to immunohistochemistry performed on paraffin blocks in France, infiltrating ductal carcinoma with a strong neuroendocrine component was confirmed by CD56, CD57, and chromogranin A markers.
\end{abstract}

\section{Introduction}

Neuroendocrine carcinomas (NECs) constitute a very rare entity, affecting mainly the bronchopulmonary system and gastrointestinal tract $[1,2]$. Breast localizations are unusual and represent less than $0.1 \%$ of mammary cancers and less than $1 \%$ of neuroendocrine tumors [1]. Most publications in radiology describe nonspecific suspicious findings and do not indicate consistent imaging characteristics of this particular carcinoma by all the available modalities, including ultrasonography, mammography, and MRI [3]. In pathology, diagnosis is based on morphological criteria and confirmed by the expression of neuroendocrine markers (chromogranin and synaptophysin) in more than 50\% of tumor cells [4]. There are two forms of breast NEC: the pure form exclusively composed of neuroendocrine cells and the mixed or composite form that is less well-differentiated $[2,4]$. The composite form often poses diagnostic difficulties, especially for laboratories lacking immunohistochemical techniques, which explains the extreme rarity of the cases reported by African authors [5]. We report a primary composite neuroendocrine carcinoma in a 13-year-old Togolese girl confirmed by immunohistochemistry. We detail the epidemiological, morphological, and immunohistochemical aspects of this rare tumor.

\section{Case Report}

A 13-year-old girl with no remarkable past medical history and no family history of breast cancer presented with a palpable mass in her right breast, which had been evolving 


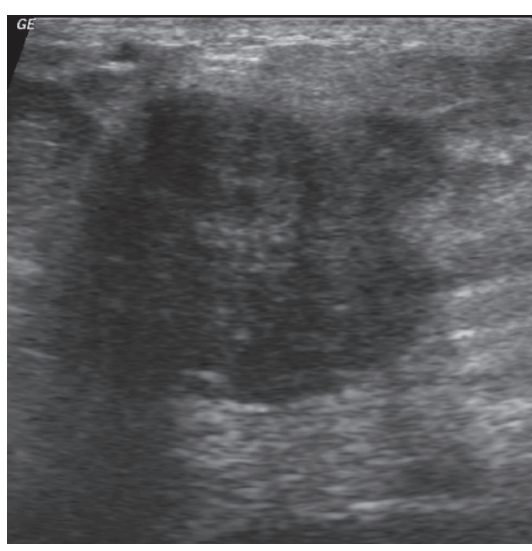

(a)

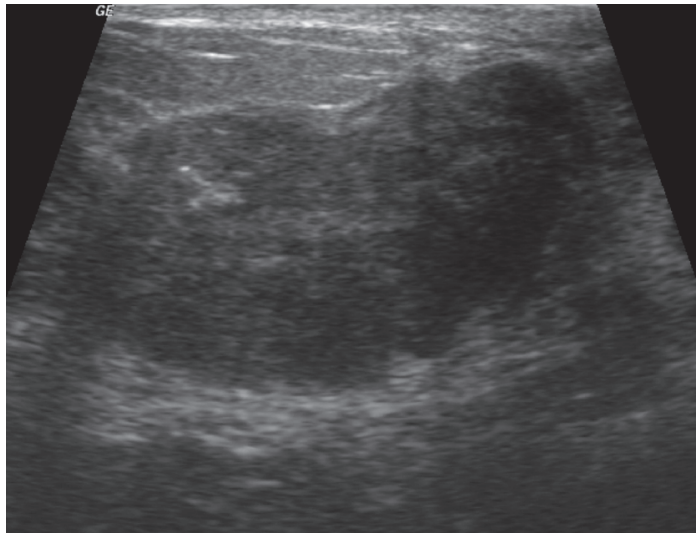

(b)

Figure 1: Transverse (a) and longitudinal (b) ultrasonography images showing a solid hypoechoic and heterogeneous mass with microlobulated contours, measuring $3.6 \mathrm{~cm} \times 2.9 \mathrm{~cm} \times 2.3 \mathrm{~cm}$, with long transversal axis of the external superior quadrant of the right breast (collection of the Department of Imaging, the University Teaching Hospital of Lomé).

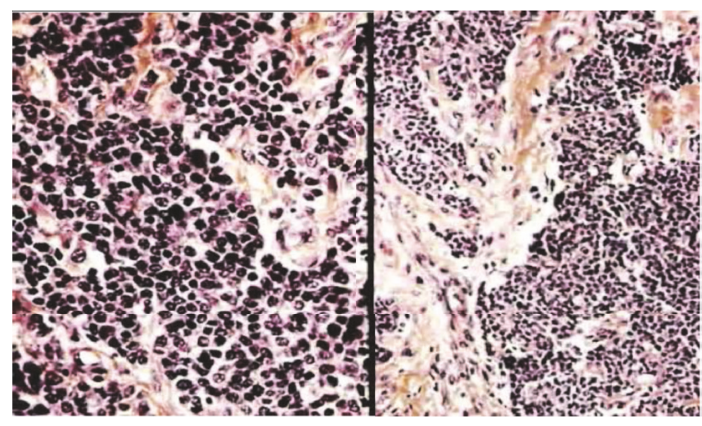

FIgURE 2: Neuroendocrine carcinoma of the breast (HES; $\times 100$ ): tumoral diffuse proliferation due to medium and large cells invading the gland and oppressing lobules and ducts (collection of the Pathological Anatomy Laboratory, the University Teaching Hospital of Lomé).

for 7 months. On physical examination, an approximately $4 \mathrm{~cm}$ firm and mobile nodule was identified. There were no axillary nodes, skin abnormality, nipple retraction, or abnormal nipple discharge. The nodule was located in the superior-external quadrant of the right breast. Due to her young age, the patient underwent only ultrasonography; no mammography was performed. Ultrasonography showed an oval hypoechoic, heterogeneous mass with microlobulated contours, measuring $3.6 \mathrm{~cm} \times 2.9 \mathrm{~cm} \times 2.3 \mathrm{~cm}$, with long transverse axis (Figure 1). The mass was considered as atypical adenofibroma and categorized as ultrasound BI-RADS 3. On the demand of the parents, an ultrasound-guided biopsy with a $16 \mathrm{G}$ automatic core needle was performed before surgical ablation. On conventional histological examination, a diffuse tumor proliferation, made up of small round cells with hyperchromatic nucleus and a scant limited amphophilic cytoplasm, massively infiltrating the gland and penetrating the lobules and channels (Figure 2) was observed. This aspect had evoked two diagnoses: primary malignant nonHodgkin's lymphoma and undifferentiated carcinoma. The

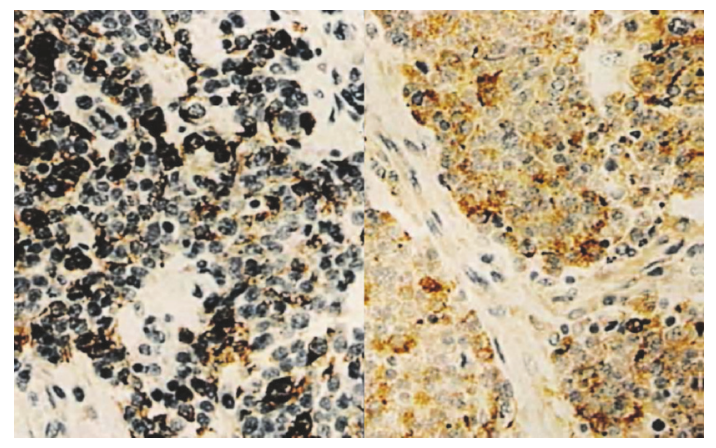

FIGURE 3: Neuroendocrine carcinoma of the breast (IHC; $\times 100$ ): chromogranin A test positive for neuroendocrine tumor cells and negative for leukocyte markers (collection of the Pathological Anatomy Laboratory, the University Teaching Hospital of Lomé).

paraffin blocks were sent to France for immunohistochemical analysis. Immunohistochemical studies demonstrated infiltrating ductal adenocarcinoma expressing cytokeratin and membrane epithelial antigen associated with a neuroendocrine population expressing CD56, CD57, and chromogranin A. The leukocyte markers were negative (Figure 3). TTF1 and CDX2 markers were not expressed by the tumor cells. Therefore, the case was a composite form of breast NEC. Abdominal ultrasound and thoracoabdominal CT scan performed excluded any secondary site or any other nonmammary primitive site. The treatment consisted of tumor surgery followed by chemotherapy. The patient died 5 months after diagnosis, owing to local recurrence and metastasis.

\section{Discussion}

NECs are very rare tumors, with an incidence of approximately 0.7 cases per 100,000 inhabitants, commonly located within the digestive tract. Mammary localization is very rare, accounting for less than $0.1 \%$ of all breast cancers and less 
than $1 \%$ of neuroendocrine tumors $[1,5]$. Our observation illustrates the diagnostic difficulties encountered in practice by underequipped pathological laboratories in Black Africa (e.g., absence of immunodetection technology and electron microscopy). Indeed, in our case, if the paraffin blocks were not sent to France, the diagnosis of NEC would be impossible to affirm. The lack of adequate technical equipment and advanced technologies in pathology laboratories noticed in the majority of African countries can explain a large part of the extreme rarity of the cases of NEC of the breast reported by African authors [6]. We reported a case of neuroendocrine carcinoma of the right breast in a young Togolese girl with fatal evolution. NEC occurrence at this age is rarely described in the literature, it is common in elderly patients, specifically between the sixth and seventh decades $[2,4,6]$.

In ultrasonography, it is common to misdiagnose breast masses, considering them as benign or probably benign lesions, or adenofibroma [7]. In these situations, fine needle aspiration biopsy or ultrasound-guided core needle biopsy is necessary $[3,7]$. In their recent literature review, ColladoMesa et al. [3] noticed that imaging features of primary neuroendocrine tumor of the breast have been previously described by only a small number of case reports [8-13]. The published cases describe nonspecific suspicious findings and do not indicate consistent imaging characteristics of this particular carcinoma. On ultrasonography, which is the only breast imaging technique performed in this case, lots of aspects have been described. The typical appearance of this cancer has been reported as a hypoechoic or heterogeneous mass, with irregular shape or microlobulated margins and with normal sound transmission $[10,14]$. In some situations, especially in older women, mammography can be crucial for the final diagnosis by revealing a distinctive mass with microcalcifications [15]. Imaging such as ultrasound, CT scan, and even PET scan if available can help in excluding another primary site of neuroendocrine tumor [15].

Histologically, the breast NEC is characterized by cell proliferation appearing as pseudorosettes invading the surrounding adipose tissue, with a richly vascularized small or fibrous stroma and small monomorphic cell elements with rather irregular nuclei and weak mitotic activity $[1,16]$. Depending on the cell type, grade, degree of differentiation, and presence of mucin production, several subtypes are defined in the WHO classification. Solid NEC, small cell carcinoma, and large cell NEC [6] have been noted. The pure form expresses a high degree of histological differentiation, whereas the composite form, apart from the neuroendocrine expression, presents either a sarcomatous component or an epithelial component $[6,17]$. Our case included a composite form of the tumor, and the histological description suggested that an undifferentiated epithelial tumor initially evoked nonHodgkin's lymphoma. In the absence of immunodetection techniques, it is difficult to confirm the diagnosis of breast NEC, especially in its mixed form, using conventional histology [17]. Even though immunohistochemical techniques have made significant progress in the diagnostic accuracy of the majority of tumors $[18,19]$, they are still inaccessible for the majority of African countries. The immunohistochemical study in our case presented several diagnostic advantages, including the positivity of the CD56, CD57, and chromogranin markers, for the diagnosis of NEC. Moreover, the immunopositivity of cytokeratin and epithelial membrane antigen indicated the epithelial component of our case, suggesting a composite or mixed form. Lastly, negative result for lymphocytic leukocyte markers made it possible to rule out non-Hodgkin's lymphoma, which was initially evoked. In practice, the distinction between the two forms of breast NEC is necessary because their prognosis is significantly different $[20,21]$. Primary neuroendocrine cancer of the breast must be distinguished from a metastatic lesion from other sites. Some markers such as TTF1 even if it is positive in only $55 \%$ of primary lung neuroendocrine tumors help to exclude lung primary NEC [15]. Positive nuclear CDX2 expression confirmed intestinal derivation [21]. Thoracic and abdominal imaging screening is helpful.

The treatment of endocrine tumors of the breast mainly comprises surgical tumor removal. The indications of chemotherapy and radiotherapy are the same as for other breast cancers. The indications of hormone therapy and immunotherapy are not coded because their effects remain uncertain [22]. In our case, the patient benefited only from surgery and chemotherapy.

\section{Conclusion}

Breast NEC is very rare and has poor prognosis. Further, its occurrence in a young patient is unusual. As there are no imaging specific features, the diagnosis of certainty is based on immunohistochemical analysis, which makes it possible to differentiate the pure forms from the composite forms. This case of a composite breast NEC also illustrates the diagnostic difficulties encountered by underequipped pathology laboratories in developing countries, explaining, in part, the extreme rarity of cases reported by African authors.

\section{Additional Points}

Availability of Data and Materials. All data generated or analysed during this study are included in this published article.

\section{Consent}

Written informed consent was obtained from the parents of the patient for publication of this case report and any accompanying images.

\section{Conflicts of Interest}

The authors declare that they have no conflicts of interest.

\section{Authors' Contributions}

Mazamaesso Tchaou and Tchin Darré are responsible for the conception of the study, participated in the study design, performed imaging and laboratory exams and interpretation, and wrote the paper. Koué Folligan, Akomola Sabi, Lantam Sonhaye, Azanledji Boumé, Akila Bassowa, and Solange 
Adani-Ifé were involved in the clinical and therapeutic management of the patient; they have reviewed the paper. Gado Napo-Koura was responsible for the overall scientific management of the study and the preparation of the final paper. All the authors have read and approved the final paper to be submitted for publication.

\section{References}

[1] M. Anlauf, M. Neumann, S. Bomberg et al., "Neuroendocrine neoplasms of the breast," Pathologe, vol. 36, no. 3, pp. 261-270, 2015.

[2] S. Singh, G. Aggarwal, S. P. Kataria, R. Kalra, A. Duhan, and R. Sen, "Primary neuroendocrine carcinoma of breast," Journal of Cytology, vol. 28, no. 2, pp. 91-92, 2011.

[3] F. Collado-Mesa, J. M. Net, G. A. Klevos, and M. M. Yepes, "Primary neuroendocrine carcinoma of the breast: report of 2 cases and literature review," Radiology Case Reports, vol. 12, no. 1, pp. 1-12, 2017.

[4] A. Inno, G. Bogina, M. Turazza et al., "Neuroendocrine carcinoma of the breast: Current evidence and future perspectives," Oncologist, vol. 21, no. 1, pp. 28-32, 2015.

[5] M. Affane, L. Elmorjani, A. El Omrani, F. Abbadi, H. Rais, and M. Khouchani, "Neuroendocrine carcinoma of the breast: about a case and review of the literature," Pan African Medical Journal, vol. 24, article 78, 2016.

[6] W. Bocker and WHO, "classification of breast tumors and tumors of the female genital organs: pathology and genetics," Verhandlungen Der Deutschen Gesellschaft Fur Pathologie, vol. 86, pp. 116-119, 2002.

[7] J. I. Malowany, U. Kundu, L. Santiago, and S. Krishnamurthy, "Fine-needle aspiration detects primary neuroendocrine carcinoma of the breast in a patient with breast implants," CytoJournal, vol. 12, no. 1, 2015.

[8] H. Ogawa, A. Nishio, H. Satake et al., "Neuroendocrine tumor in the breast," Radiation Medicine, vol. 26, no. 1, pp. 28-32, 2008.

[9] H. Ajisaka, K. Maeda, A. Miwa, and K. Yamamoto, "Breast cancer with endocrine differentiation: report of two cases showing different histologic patterns," Surgery Today, vol. 33, no. 12, pp. 909-912, 2003.

[10] I. Gunhan-Bilgen, O. Zekioglu, E. Ustun, A. Memis, and Y. Erhan, "Neuroendocrine differentiated breast carcinoma: imaging features correlated with clinical and histopathological findings," European Radiology, vol. 13, pp. 788-793, 2003.

[11] A. Irshad, S. J. Ackerman, T. L. Pope, C. K. Moses, T. Rumboldt, and B. Panzegrau, "Rare breast lesions: correlation of imaging and histologic features with WHO classification," Radiographics, vol. 28, no. 5, pp. 1399-1414, 2008.

[12] A. Mariscal, E. Balliu, R. Díaz, J. D. Casas, and A. M. Gallart, "Primary oat cell carcinoma of the breast: Imaging features," American Journal of Roentgenology, vol. 183, no. 4, pp. 1169-1171, 2004.

[13] J.-Y. Zhang and W.-J. Chen, "Bilateral primary breast neuroendocrine carcinoma in a young woman: report of a case," Surgery Today, vol. 41, no. 11, pp. 1575-1578, 2011.

[14] E. D. Chang, M. K. Kim, J. S. Kim, and I. Y. Whang, "Primary neuroendocrine tumor of the breast: Imaging features," Korean Journal of Radiology, vol. 14, no. 3, pp. 395-399, 2013.

[15] L. Marinova, D. Malinova, and S. Vicheva, "Primary neuroendocrine carcinoma of the breast: histopathological criteria, prognostic factors, and review of the literature," Case Reports in Pathology, vol. 2016, Article ID 6762085, 4 pages, 2016.

[16] Y. Fujimoto, R. Yagyu, K. Murase et al., "A case of solid neuroendocrine carcinoma of the breast in a 40-year-old woman," Breast Cancer, vol. 14, no. 2, pp. 250-253, 2007.

[17] O. David and M. Bhattacharjee, "Diffuse neuroendocrine differentiation in a morphologically composite mammary infiltrating ductal carcinoma: a case report and review of the literature," Archives of Pathology \& Laboratory Medicine, vol. 127, no. 3, pp. 131-134, 2003.

[18] A. Galzerano, N. Rocco, A. Accurso et al., "Medullary breast carcinoma in an 18-year-old female: Report on one case diagnosed on fine-needle cytology sample," Diagnostic Cytopathology, vol. 42, no. 5, pp. 445-448, 2014.

[19] S. Frachon, D. Pasquier, I. Treilleux et al., "Breast carcinoma with predominant neuroendocrine differentiation," Annales de Pathologie, vol. 24, no. 3, pp. 278-283, 2004.

[20] K. Alva, L. Tauro, P. Shetty, and E. Saldanha, "Primary neuroendocrine carcinoma of the breast: a rare and distinct entity," Indian Journal of Cancer, vol. 52, no. 4, pp. 636-637, 2015.

[21] S. C. Wentz, C. Vnencak-Jones, and W. V. Chopp, "Neuroendocrine and squamous colonic composite carcinoma: Case report with molecular analysis," World Journal of Gastroenterology, vol. 17, no. 42, pp. 4729-4733, 2011.

[22] S. Kinoshita, A. Hirano, K. Komine et al., "Primary smallcell neuroendocrine carcinoma of the breast: report of a case," Surgery Today, vol. 38, no. 8, pp. 734-738, 2008. 


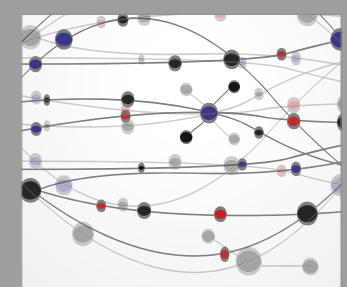

The Scientific World Journal
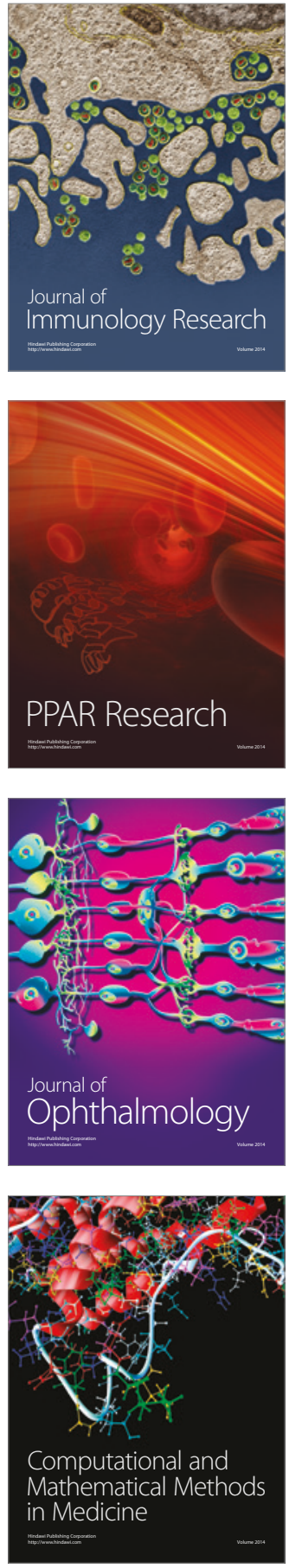

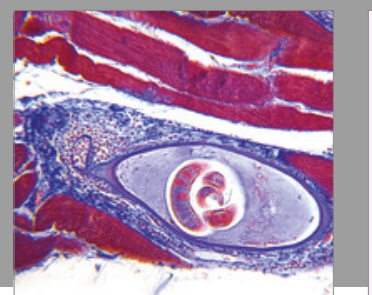

Gastroenterology Research and Practice
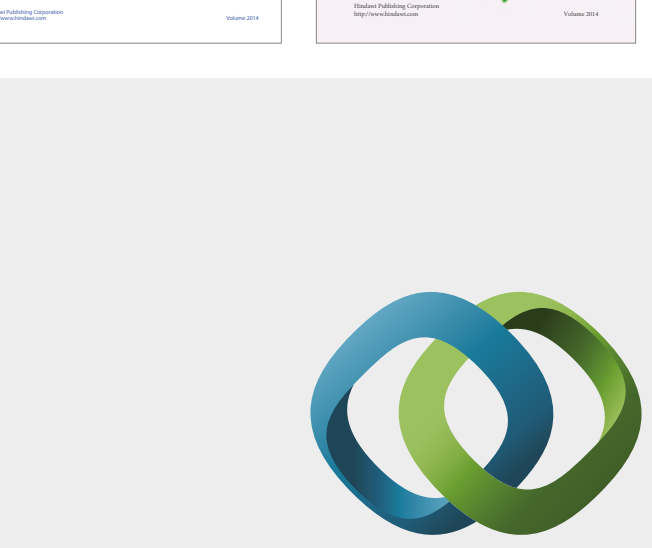

\section{Hindawi}

Submit your manuscripts at

https://www.hindawi.com
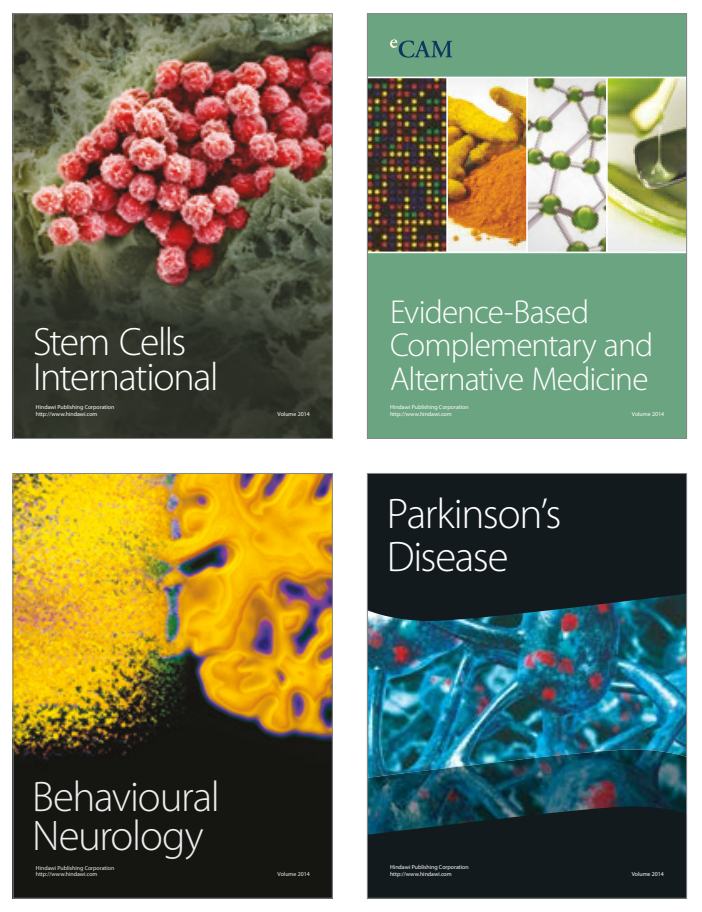
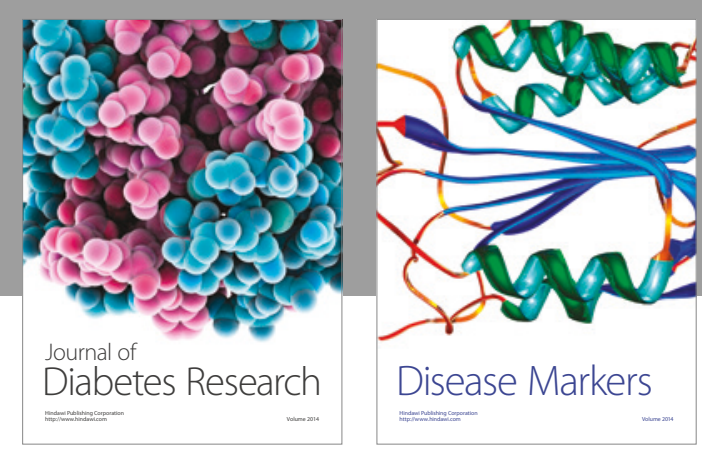

Disease Markers
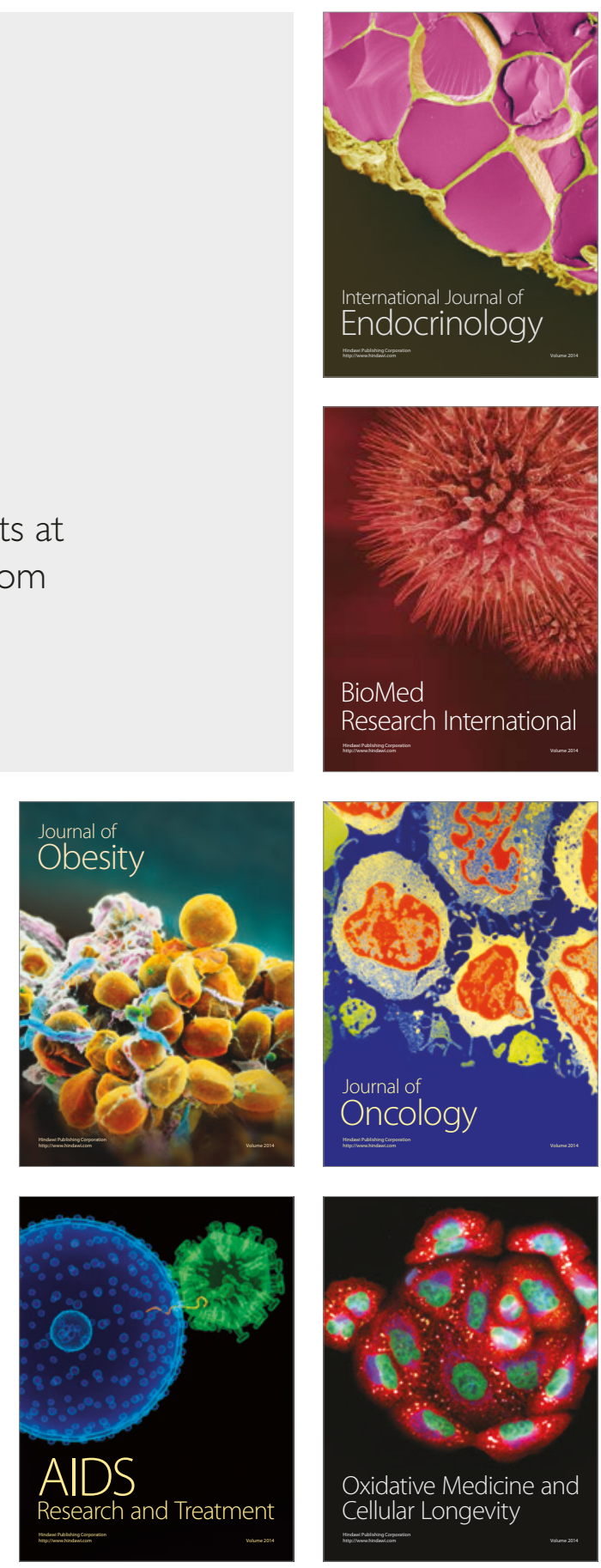